Improved freeze-thaw characteristics show as a lower rate of sedimentation after freezing, and better gloss and transparency of the paste.

The new properties of amylopectin obtained by cross-linking can be explained by a greatly reduced rate of retrogradation and greater internal rigidity of the starch molecule. The technique of cross-linking can be extended to dextrines, which are used as remoistening gums on envelope flaps and labels. The deterioration of such gums on ageing has been shown to be due to retrogradation of the dextrine in the presence of small amounts of water. By using the hydroxyethyl derivative of dextrines for gumming purposes, the ageing characteristics of flap gums can be largely avoided. Finally, Dr. Schoch explained how starch films, which have been laid down by slow evaporation of water, have a greatly increased resistance to water when compared to quickly dried films. This again can be shown to be due to retrogradation taking place during the slow drying of films.

Prof. M. Samec (Ljubljana, Yugoslavia) described how the bursting and tear strength of paper can be markedly improved by using a starch size which has been previously irradiated with cobalt-60. This process might become of great importance if the cost of the radioactive material would be reduced in the future.

The use of starch as sizing agent in the paper industry was described by J. Seaman (Slough, Bucks). A beater size should preferably be a potato starch soluble in cold water, of which 5 per cent $w / w$ is added to the paper pulp. Such starches are manufactured by passing a slurry containing starch and borax over steam-heated drying rolls. The product when re-dissolved has $p \mathbf{H} \mathbf{8 . 5}$ at 5 per cent concentration. For surface sizing it is advantageous to use an oxidized starch, which is manufactured by treating potato starch with sodium hypochlorite. The material has to be cooked with water before use to give a size having $p \mathbf{H} 7.5$ at 15 per cent solid-content. For paper coating, white potato dextrine (1 part) is added to china clay (5-6 parts) and the mixture made up with water to a slurry having a solid content of 50 per cent.

When selecting dextrines for coating purposes, it is essential to choose one with a maximum rate of set back to enable the coating to set on the surface of the paper as rapidly as possible.

Prof. M. Mautner (Zagreb, Yugoslavia) described a new method for the continuous production of glucose by the acid hydrolysis of starch. The starch slurry is first treated with hydrochloric acid and is then passed into a conical chamber, which rotates very quickly about its long axis. The chamber is heated externally by steam and is provided with an inlet at the wide end and an outlet at its apex. Ungelatinized starch particles are forced by centrifugal force to the walls of the chamber, where they gelatinize instantly. In so doing their specific gravity is reduced and they are replaced by further ungelatinized granules. The chamber has a peripheral speed of $30 \mathrm{~m}$. $/ \mathrm{sec}$. and it can deal with $2 \frac{1}{2}$ tons of raw starch per hr. After leaving the chamber the starch paste is fed into a series of flat, box-like heat exchangers, where the final conversion of starch to glucose takes place. It is estimated that the total time required for conversion is only $18 \mathrm{~min}$.

At the Convention a total of twenty-two papers was read and they will be reprinted in full in the journal Die Stärke.

The actual Convention was followed during April 24-25 by the first meeting of the International Standards Organization Technical Committee No. 93, which has been set up to establish international recommendations for analysis of starch, including its derivatives and by-products. There were 65 delegates present from Czechoslovakia, Denmark, Eire, Finland, France, Germany, Hungary, Italy, India, The Netherlands, Norway, Switzerland and the United King. dom. The chair was taken by Prof. K. Heyns (Hamburg), the secretariat being held by the German Standards Association. The British side of the work is in the hands of the British Standards Institute Committee on Analysis and Testing of Starch Products ; ten members of this committee-representing manufacturers and users of starch and associated products, research interests and Government departments-were present. The work already done by the British Standards Institute Committee enabled the British delegation to give a strong lead at these inaugural discussions of the International Standards Organization and many of the United Kingdom proposals were adopted.

It was agreed that the scope of the new International Standards Organization committee should cover : terminology, methods of sampling, methods of analysis and examination of starch, its derivatives (including hydrolysis products and dextrines) and its by-products.
E. Dux

\title{
THE EDUCATION OF TECHNOLOGISTS
}

$\mathrm{T}$ HE presidential address to the Institution of Metallurgists, delivered by Prof. A. J. Murphy on May 12, covered a field involving not only the metallurgist but also the technologist in general, and in no small measure the pure scientist as well.

After dealing with matters of a more or less domestic nature, Prof. Murphy turned his attention to the general background desirable in the training of the technologist. From this the following has been extracted.

Sooner or later in any discussion on the education of scientists and technologists the remark will be made : "What a pity it is that you cannot give your bright young technical men some sense of cultural values". Often this can be recognized as the defensive manœuvre of a dyed-in-the-wool classicist, who, in an age of automation, atomic energy and satellites, sighs for the day when he could with impunity, and publicly, dismiss science as something they used to call "stinks" at school.

But there is more in it than that. It must be admitted that far too many technically competent men are distressingly inept in communication by speech and writing. This is very regrettable. The blame rests primarily on the schools - of that I do not have the slightest doubt. I do not believe that any reasonably intelligent boy who had been properly taught the elements of English grammar and syntax could perpetrate the mangled compositions which 
one encounters alike in Ph.D. theses and the scripts of technical representatives. As for some of the efforts at reported speech which one receives from secretaries of technical committees, one can only regret that the writers have not been able to experience the intellectual satisfaction to be gained from a proper appreciation of the sequence of tenses. The Institution of Metallurgists is trying to do something toward remedying this state of affairs by requiring the demonstration of at least a modest competence in the use of the English language as part of the qualification of a metallurgist. We must hope that by gradual seepage down the line this measure will encourage the schools to increase their efforts in teaching English for use.

We are all fully persuaded that premature and immoderate specialization can produce monsters. Once such damage has been done there is not much hope for rescue operations conducted in university faculties of science and engineering or in technical colleges. Again I think we must look to the schools for salvation. An awareness of what goes on outside his specialization ought to have been gained in the technologist's school days. Special lectures of one hour a week in the liberal arts, isolated from the technological course, make no appreciable impression on deficiencies in this respect which the student has brought with him to the university or technical college.

Somehow time must be found, or regained, in the schools for these opportunities to taste the many savours which go to make a full life. The late Prof. Samuel Alexander said that liberality was the "spirit of pursuit, not a choice of subject". Sir Eric Ashby, in a series of stimulating papers, and lately in his book "Technology and the Academics", has denied that technology and culture are antitheses, and has urged that technology properly taught can provide a path to eulture through a man's specialization and not by by-passing it. In this respect technology has the advantage over pure science in its opportunities for developing cultural appreciation, since applied science necessitates contact with one's fellow-men outside one's specialization. If the technologist is to achieve the successful application of his science he must study his fellow man in order to understand his desires, his fears and his needs.

To the man whose training has been along the route of an apprenticeship and a Higher National Certificate qualification, corporate membership of a professional institution opens a door to promotion to positions of major responsibility which otherwise would remain closed. Much could be written about our neglect, during the thirty years or so before and after the beginning of the century, to appreciate the immensely valuable national asset which we possessed in this type of man, and we may yet have cause to regret our improvidence. Apprenticeship in the engineering and metallurgical industries fell into sad disrepute in those days. Less and less did it serve as a springboard for advancement to executive appointments save for men of exceptional ability, whorn no system, however bad, could have held back; more and more it became merely a procedure for instilling into the youngster the minimum technical knowledge which operative employment required. In our time we see a new approach. Positive action is taken to encourage and help the young man in industry to broaden his educational horizon and to aim at the most ambitious target which his intellectual ability brings within his scope.

It is a good thing from time to time to count one's blessings. It adds zest to the enjoyment of good times and it helps to keep one's sense of proportion when things are not going so well. Sometimes a piece of good fortune is too obvious to be overlooked. There are also those blessings which become evident only after a little reflexion. In this category comes the privilege which we enjoy in a calling in the absorbing world of science and technology. It is indeed a happy circumstance for us that we make our livings by engaging in an occupation which commands our great interest, even apart from the tangible rewards which economic necessity compels us to exact. When we contemplate the lot of many of our fellow-citizens who must earn their daily bread by the performance of ineffably dull chores, then surely we cannot deny the boon with which by contrast we are favoured.

\section{VISUAL ILLUSTRATION OF UNIVERSITY LECTURES}

\begin{abstract}
$\mathrm{A}^{\mathrm{T}}$ T the annual general meeting of the British Universities Film Council, held at University College, Cardiff, on May 8 and 9 , one session was devoted to a discussion, under the chairmanship of Prof. G. E. H. Foxon, on the problems of illustrating university lectures by film and related techniques. It was attended by several guests as well as tho representatives of the universities on the Council.

Opening the discussion, the guest lecturer, Mr. C. E. Fngel, of the Department of Medical Illus. tration, Guy's Hospital Medical School, and editor of Medical and Biological Illustration, took as his subject "The Lecture Theatre of the Future". $\mathrm{He}$ pointed out that considerable information was now available on several matters influencing design of lecture theatres, including the visibility of blackboards and of projection screens of different materials. The value of the 'recessed' type of screen was particularly stressed as it allows of sufficient illumination
\end{abstract}

in the theatre for note-taking without impairing the quality of the projected image. Methods involving complicated arrangements of projection are usually considered unsuitable for university use because they upset the speed of the lecture and come between the lecturer and his audience by interposing another person as projectionist. Several devices to overcome this trouble were demonstrated, including : first, a projector for 2 in. $\times 2$ in. slides with automatic slide change and change of focus; and secondly, the prototype of a magazine loading projector for loop films. The details of operation of this loop projector. were demonstrated in close-up by closed-circuit television (with apparatus kindly lent by the Marconi Wireless and Telegraph Company), thereby showing another method of lecture illustration. Mr. Engel concluded by pointing out the need for a magazineloading cine-projector operated by the lecturer by remote control so that the film sequence could be 